\title{
Vídeos educacionais indexados por Sintagmas Nominais permitindo a navegação no interior da mídia
}

\begin{abstract}
This article presents a proposal of video indexation by content using the indexation politics by SN (nominal groups). Opted for $S N$, because besides allowing the consultation through key-words to locate a certain video scene the systemprovides the user to navigate inside the video in an hypertext way and the SN are more appropriate for these two forms that the system can be explored. Three experiences of indexation of videos by content are presented: SVL (Searchable Video Library) of the University of Arizona, TV school and SACCA (Automatic System of Cataloguing of Audiovisual Content).
\end{abstract}

Resumo. Este artigo apresenta uma proposta de indexação de vídeo por conteúdo utilizando a política de indexação por SN (Sintagmas Nominais). Optou-se por SN, pois além de permitir a consulta por palavras-chaves para localizar uma determinada cena do vídeo o sistema possibilita ao usuário navegar no interior do vídeo de forma hipertextual e os SN são mais apropriados para essas duas formas que o sistema pode ser explorado. São apresentadas três experiências de indexação de vídeos por conteúdo: SVL (Searchable Video Library) da Universidade do Arizona, TV Escola e SACCA (Sistema Automático de Catalogação de Conteúdo Audiovisual).

\section{Introdução}

Atualmente existe um acervo muito grande de vídeos educacionais. Uns disponibilizados pela TV Escola, outros produzidos nas Universidades e Escolas. Vídeos com conferências, aulas, experimentos, demonstração de procedimentos, documentários e visitas em campo estão proliferando, mas ficam muitas vezes sem serem usados pelo desconhecimento de seu conteúdo pela potencial população de usuários, como os professores e os alunos. Pretto comenta que existe uma gama de produções que ficam guardadas na universidade local sem serem usadas pelas outras universidades para compartilharem o uso das produções. Ele afirma que "a distribuição do material audiovisual disponível, seja de produção própria ou não, ganharia nessa perspectiva uma dimensão maior" [Pretto 1996, p. 227].

Além disso, a busca de vídeos possui alguns limitantes, como a dificuldade de encontrar cenas ou conteúdos em um filme com longa duração. Adicionalmente, professores encontram dificuldades em localizar vídeos adequados ao conteúdo da aula em videotecas com grande acervo.

Com isso, o desenvolvimento e a implementação de métodos para indexação de vídeo passa a ser muito útil, pois disponibilizaria esses vídeos na internet, onde um número muito maior de pessoas poderia ter acesso, acrescentando ainda uma maior rapidez, agilidade e precisão às procuras (consultas) feitas por professores ou alunos em um repositório de vídeos digitais, se comparado com a busca em videotecas de fitas de vídeo.

Além da facilidade de localização dos vídeos, há a quebra da linearidade ao assistir ao vídeo, bastante criticada por alguns educadores, pois o aluno torna-se um 
sujeito passivo ao ser um mero telespectador. O vídeo indexado dá uma nova postura para esse aluno; ele irá interagir com o conteúdo, tornando-se um sujeito ativo.

Os vídeos com um índice associado, permitindo a navegação no interior da mídia tal como ocorre na internet, com uma maior facilidade de retomar determinado ponto, ir para outro ponto e repetir determinada cena, seriam de grande valia para a aprendizagem do aluno. "Crianças e jovens, que navegam intensamente pela internet, vêem muita TV e participam de contínuos jogos eletrônicos, pensam de uma forma mais sensorial, concreta, plástica, multimídica, "linkada", coloquial" [Moran 2005, p. 98].

Em geral os vídeos possuem uma enorme variedade de frases ou idéias que podem servir de índice. Um item do índice pode ser qualquer palavra que conste do vídeo, sendo de vital importância que esta palavra represente, de uma forma geral, o significado do conteúdo do vídeo.

A construção desse índice, diferente do que, em princípio, vem ocorrendo, refere-se ao produtor do índice e não ao seu destinatário, o usuário do sistema de informação. O destinatário da informação não é obrigado a conhecer a linguagem de indexação utilizada, ou, ainda, os recursos de informática, ou as políticas biblioteconômicas [Lan and Krieger 2002].

A política de indexação utilizada para criar os índices dos vídeos de História do Brasil disponibilizados pelo TV Escola levou em consideração o seu destinatário, professores de História do Ensino Fundamental e os alunos desses professores. Para isso, optou-se por usar sintagmas nominais $(\mathrm{SN})$ em vez de descritores. SN "é a menor parte do discurso portadora de informação" [Kuramoto 2002, p 6].

Para uma melhor representação do significado do texto, é importante que essa palavra ou conjunto de palavras seja suficiente para a identificação do tema ou assunto principal do documento. Para Grefenstette (1994), as possibilidades de diferentes sentidos, quando os termos são múltiplos, são menores do que o sentido de uma única palavra. SN é um forte candidato a conter palavras com significado.

Consideramos os sintagmas nominais como a melhor alternativa para a indexação de vídeos educacionais, pois além da pesquisa por palavra-chave (possibilitando saber em que contexto a palavra-chave esta inserida) é possível a navegação no interior do vídeo com uma maior qualidade, comparando se esse índice fosse feito com descritores, permitindo ter uma visão rápida do que o vídeo trata.

\section{Bibliotecas Digitais e Repositórios de Vídeos}

Antigamente apenas disponível em fitas, o vídeo só possibilitava acesso seqüencial. Um aparelho de vídeo-cassete só é capaz de "navegar" pelo material avançando ou retrocedendo a fita. $\mathrm{O}$ armazenamento de vídeos em computador proporcionou o acesso a esse material de forma mais sofisticada.

Os vídeos digitais são armazenados em repositórios multimídia, porém o conceito de repositório multimídia é por vezes confundido com o de biblioteca digital.

Biblioteca Digital é uma coleção organizada de informações armazenadas de forma digital e não apenas um grande repositório de dados [Paepcke 1996]. Podemos dizer que estas bibliotecas “... são organizações que provêem os recursos, inclusive o pessoal especializado para selecionar, estruturar, preservar a integridade e assegurar a persistência com o passar do tempo de coleções digitais, de forma que estejam pronta e economicamente disponíveis para uso por uma comunidade definida" [Clir 2000]. 
Quase todo tipo de informação ou dado pode ser representado no formato digital, incluindo textos, músicas, imagens, vídeos e trabalhos compostos combinando vários tipos de dados. Numa biblioteca digital, os dados são armazenados como objetos digitais. Cada objeto digital possui uma estrutura que armazena seu conteúdo. As informações que descrevem um objeto ou conjunto de objetos são denominadas metadados [Osses 2000].

Uma biblioteca digital pode ser constituída de vários repositórios de dados, porém a recíproca não é verdadeira. Repositório de dados é um subconjunto de uma biblioteca digital. Poderemos procurar por um vídeo em uma biblioteca digital ou em um repositório multimídia, porém o vídeo estará armazenado fisicamente em um repositório multimídia.

Neste artigo, iremos falar somente das bibliotecas digitais que disponibilizam vídeo no seu acervo e dos repositórios de vídeos educacionais. Tanto as bibliotecas digitais quanto os repositórios de vídeos educacionais podem disponibilizar a consulta aos vídeos de duas maneiras: busca realizada por metadados do vídeo (autor, título, resumo, etc.) ou busca realizada pelos metadados que se encontram no interior do vídeo. Como esse é um dado de relevância para este artigo, serão mostrados somente as bibliotecas digitais e os repositórios de vídeos educacionais que possuem a característica de busca por conteúdo.

A indexação do Searchable Video Library (SVL) ocorre por extração automática de texto que esteja na língua inglesa. A experiência da TV Escola se dá por quebra do vídeo em cenas permitindo ter uma visão do todo do vídeo (já que ele define uma imagem associada a cada cena, uma explicação da cena e um título para as diversas cenas que compõem o vídeo). No CESTA (Coletânea de Entidades de Suporte ao uso de Tecnologia na Aprendizagem), a indexação é feita ao se associar SN aos quadros mais significativos do vídeo. Tanto na experiência da TV Escola quanto no CESTA, há intermediação de um usuário para definir as descrições.

\subsection{Biblioteca de Vídeos da Universidade do Arizona}

O Searchable Video Library (SVL), desenvolvido pela Universidade do Arizona, é um serviço que permite fornecer aos estudantes acesso a vídeos e a aulas gravadas de professores através do site http://vlweb1.vala.arizona.edu/vss-bin/vss_SR/torpey/search.

Os vídeos são catalogados automaticamente, o áudio do vídeo é analisado e palavras-chaves são identificadas e localizadas no tempo. Para isso, é usado um software comercial chamado VIRAGE. Embora o catalogador seja extremamente eficiente, ele não cria uma transcrição legível; o aprendiz deverá prestar atenção e escutar o vídeo para compreender o índice. Este software funciona somente na Língua Inglesa.

O site SVL utiliza o algoritmo de busca do AltaVista. A página dos resultados mostra os vídeos que possuem a palavra-chave digitada no site de busca. É mostrado em qual instante do vídeo aparece a palavra-chave.

A janela de visualização do vídeo mostra, na parte superior, uma descrição introdutória do filme; na direita, mostra o vídeo dividido em cenas e, na parte esquerda e inferior, as partes do vídeo com o texto correspondente em cada ponto. O texto pode não ter muito sentido, porém as palavras e as frases importantes podem ser encontradas. 


\subsection{TV Escola}

A TV Escola disponibiliza vídeos indexados no site http://www.icad.pucrio.br/tvescola/. São vídeos que tratam da saúde da pele a partir do projeto Homem Virtual, desenvolvido pela Faculdade de Medicina da USP. Este site disponibiliza apenas 7 vídeos indexados.

A indexação executada pelo site é a segmentação do vídeo em diversos trechos e, para cada trecho, é definida uma imagem, um título e uma breve descrição.

O usuário identifica o trecho do vídeo que ele deseja visualizar e, ao clicar em cima da imagem, é feito download daquele pedaço do vídeo para a máquina do usuário. Ele visualizará o vídeo na janela do navegar. Este processo é bastante demorado.

Outra dificuldade ocorre se o usuário desejar assistir ao vídeo inteiro. No site não tem essa opção. Ele disponibiliza o vídeo em pedaços e o usuário só consegue assistir a ele dessa forma.

\subsection{CESTA}

Diferente da indexação do SVL, que armazena o texto falado no vídeo e do TV Escola, que se dá pela quebra do vídeo em partes, no CESTA a indexação é por SN.

Ao entrar na tela de login do $\operatorname{CESTA}^{1}$, o usuário terá a opção de consultar vídeos e outros objetos educacionais por palavras-chaves. Ao realizar uma consulta pela palavra "Pedro" é apresentada uma tela que mostra os objetos educacionais que possuem essa palavra-chave. O resultado da consulta por esta palavra disponibiliza seis vídeos.

Se a busca for pela palavra "Cabr", o sistema também irá localizar os vídeos que possuem esse pedaço de palavra no seu interior. O resultado dessa consulta no CESTA trouxe quatro vídeos que apresentam a palavra Cabral no seu conteúdo: Caminhos da riqueza (História - Brasil 500 anos: um mundo na TV), A cor do pau-brasil (História Brasil 500 anos: um mundo na TV), Encontro no além-mar (História - Brasil 500 anos: um mundo na TV) e História do Brasil por Boris Fausto.

Ao clicar no link "Ver vídeo indexado", o vídeo será executado a partir do ponto em que ocorre aquela palavra. O professor ou o aluno também poderá navegar pelos outros links do vídeo. Se o vídeo não estiver bufferizado na máquina do usuário, ele será apresentado no início. Ao clicar em "Ver vídeo indexado" do vídeo "Colônia" será apresentado o vídeo com os seus respectivos SN, como mostra a Figura 1.

\footnotetext{
${ }^{1}$ http://cesta.cinted.ufrgs.br/cesta.login.php - Usuário: guest - Senha: guest
} 


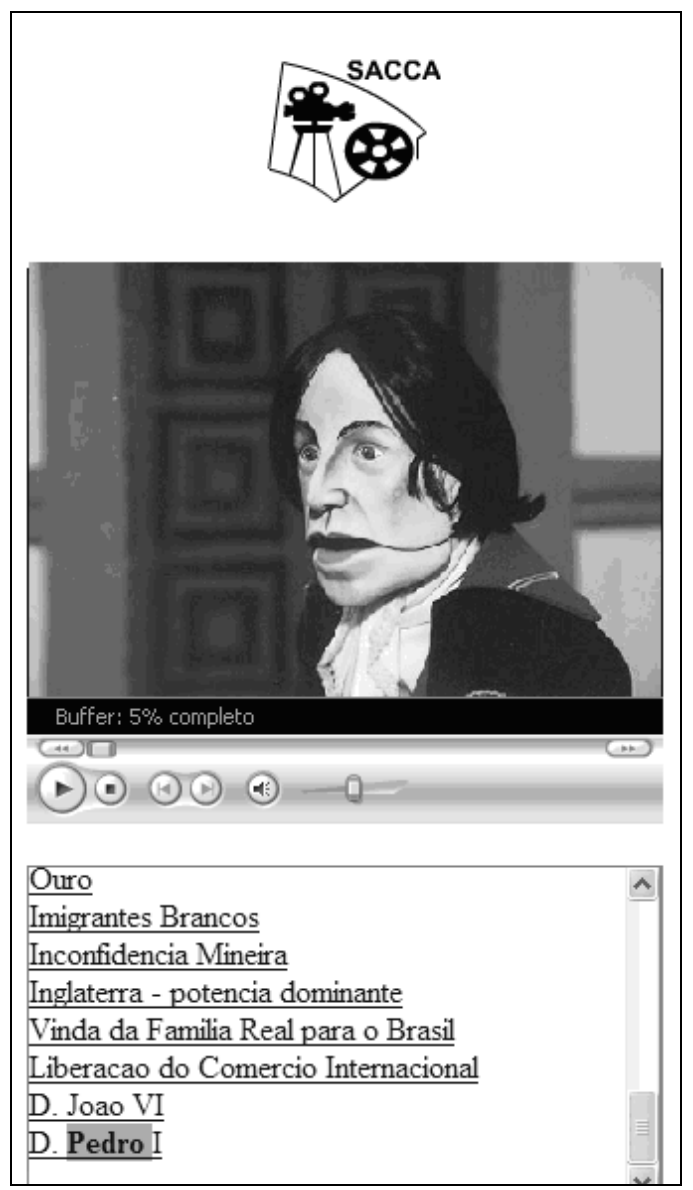

Figura 1. Vídeo "Colônia" selecionada a palavra-chave "Pedro"

Além de localizar no interior do vídeo alguma cena pela palavra-chave, uma outra facilidade do SACCA consiste em o professor poder visualizar sobre o que trata o filme de forma rápida. Os links que estão no interior do vídeo facilitam a navegação permitindo que o professor tenha uma visão geral do que o vídeo apresenta.

Existem críticas quanto ao vídeo disponibilizado de forma linear. Fischer (1998) chama a atenção dos professores para não tratar o vídeo em sala de aula de forma absolutamente linear e instrumental. Para Neves (2005), o vídeo digital faria com que mudasse a postura do observador de passivo para aquele que tem o controle de como quer assistir ao filme. Concordando com a idéia das autoras, acreditamos que o vídeo indexado resolveria o problema quanto ao aluno ser um sujeito passivo ao assistir o filme, tornando-se sujeito ativo ao poder navegar no seu interior.

A Biblioteca de Vídeos da Universidade do Arizona possui a catalogação automática de conteúdo do vídeo. O áudio do vídeo é analisado e palavras-chaves são identificadas e localizadas no momento em que são faladas. É usado um software comercial VIRAGE, para fazer a análise, mas este software somente funciona para a língua inglesa. Todavia o resultado é muito relevante, pois possibilita ao aluno digitar uma ou mais palavras-chaves e receber uma coleção de URLs que apontam para vídeos armazenados no repositório (incluindo pontos específicos do vídeo onde a palavra é dita). Outra experiência de indexação de vídeos por conteúdo no Brasil é a da TV Escola, que divide o vídeo em partes e associa a cada uma dessas partes um título, uma 
imagem e um texto resumido. Apresenta diversas desvantagens: só possui 7 vídeos indexados; não existe um local para se digitar as palavras-chaves que se deseja procurar no vídeo; a indexação é feita quebrando o vídeo em pedaços, se o usuário desejar assistir ao vídeo inteiro, terá que olhar um pedaço, depois outro pedaço; a visualização do pedaço do vídeo é muito demorada, pois é feito o download em vez de ser disponibilizado o vídeo por streaming e, além disso, a quebra do vídeo ocorre em pedaços muito grandes.

O SACCA, tal como acontece com a Biblioteca de Vídeos da Universidade do Arizona, possibilita ao aluno digitar uma ou mais palavras-chaves e receber uma coleção de URLs que apontam para os vídeos armazenados no repositório (incluindo pontos específicos do vídeo onde a palavra é dita) e disponibiliza os vídeos com a tecnologia streaming. Diferente da indexação fornecida pela TV Escola, a indexação é realizada associando SN em quadros do vídeo (se tendo um número maior de palavraschaves associadas ao vídeo). Ao visualizar o vídeo, esses SN funcionam como links, sendo possível o usuário navegar no interior do vídeo.

O SACCA foi agregado ao CESTA, pois este é um sistema de Recuperação de Informação (SRI), mas especificamente, um sistema de recuperação de objetos educacionais.

Uma outra grande diferença verificada nesses repositórios é quanto à agilidade na visualização dos vídeos que se deseja consultar. Se as bibliotecas e repositórios disponibilizam os seus vídeos na forma de streaming, essa visualização é muito mais rápida. Por outro lado, nas bibliotecas em que os vídeos são disponibilizados para download num primeiro momento, esse processo de identificar se o vídeo se encaixa dentro da temática que o usuário está procurando é bastante demorado. A Biblioteca de Vídeos da Universidade do Arizona e o CESTA disponibilizam os seus vídeos com a tecnologia streaming. Na TV Escola os vídeos são disponibilizados para download.

\section{Política de Indexação}

Em geral os vídeos possuem uma enorme variedade de frases ou idéias que podem servir de índice. Um item do índice pode ser qualquer palavra que conste do vídeo, sendo de vital importância que esta palavra represente, de uma forma geral, o significado do conteúdo do vídeo. Meadow et al. (2000) confirma essa idéia ao falar da indexação de textos: "os termos que representam o assunto do texto podem ser usados como índice do texto".

Um índice é um conceito ou uma coleção de palavras associadas a ponteiros para recuperação rápida de informação [Baeza and Yates 1999]. Um índice pode ser qualquer palavra de um documento, sendo de vital importância que esta palavra represente, de uma forma geral, o significado do conteúdo do documento.

Para indexar um livro, um artigo de jornal, um relatório técnico, um vídeo, são registrados valores de vários atributos que possam depois ser usados como base na pesquisa. Esses valores "são palavras e/ou grupos de palavras chamados de descritores e, muitas vezes, de palavras-chave" [Kuramoto 1995, p.3].

A consulta por palavra-chave é a consulta por uma palavra única, quando o sistema busca essa mesma palavra em um determinado contexto [Baeza and Yates 1999], porém a definição das palavras que representaram as cenas dos vídeos foi definida seguindo uma política de indexação. 
A determinação de uma política de indexação fundamenta-se, principalmente, em três fatores: objetivos da instituição e da unidade de informação, perfil do usuário, área temática de abrangência do sistema e os textos a serem indexados [Lan and Krieger 2002].

A análise desses fatores, entre outros pontos, irá definir o tipo de linguagem de indexação que será utilizada. Linguagem de indexação é um sistema de signos estruturados, cuja finalidade é representar e recuperar as informações registradas nos documentos [Lan and Krieger 2002].

Perini (1996) define SN como uma classe gramatical com comportamento sintático de sujeito, de objeto direto e, se precedido de preposição, de adjunto adnominal ou de objeto indireto. Segundo Liberato (1997), o SN é a parte do enunciado que representa um conceito ou referente. Os referentes podem ser entidades abstratas ou concretas; podem ser identificados por nomes próprios ou através de um SN descritivo; e podem ter uso referencial, representando uma entidade, ou uso atributivo, representando um papel.

Os sintagmas nominais possuem uma estrutura sintática, podendo ter diversas configurações em termos sintáticos. Um exemplo de sintagma nominal é apresentado a seguir em [Kuramoto 2002]:

I. O estudo da economia da informação

Trata-se de um sintagma nominal complexo, pois dois outros sintagmas nominais encontram-se embutido nele:

\section{A economia da informação}

III. A informação

Diferentemente dos descritores, o sintagma nominal, quando extraído do texto, mantém o significado, o seu conceito [Kuramoto 2002].

A definição desses SN para os vídeos de História do Brasil do TV Escola foi feita por um professor de História de Ensino Fundamental, pois, segundo Laan et al. (2004, p. 337), "se não houver sintonia entre os termos utilizados pelo indexador para representar e os termos utilizados pelo usuário para buscar, as informações que esses termos representam ficarão irremediavelmente perdidas".

Optou-se pelos SN em vez dos descritores, pois realizar o controle de vocabulário e buscar a univocidade comunicacional é apagar a riqueza vocabular própria das comunicações humanas [Lan and Krieger 2002]. Cintra et al. [1994, apud Lan and Krieger 2002, p. 77] afirma que os descritores estão desvinculados dos textos "que lhes deram origem". Ainda segundo os mesmos autores, "o descritor apresenta sentidos isolados: de um lado, estão desvinculados dos textos; de outro, submetem-se a uma organização segundo referenciais externos a eles". Isso dificulta o processo de comunicação entre o usuário e a sua consulta no SRI [Laan et al. 2004]:

(...) os atuais descritores estão sendo determinados em conformidade com o princípio de univocidade, por isso caracterizados pela monorrefencialidade, ou seja, apenas um código é empregado para representar cada conceito. Dessa forma, perde-se toda a riqueza vocabular que existe, mesmo se tratando de léxico especializado (2004, p. 338). 
Segundo Coulon e Kayser (1992), as palavras de um texto e de um vídeo podem-se dividir em duas categorias: as que possuem significado e as demais. Entre as palavras que possuem significado estão palavras (ou conjuntos de palavras) normalmente com sentido substantivo que, segundo Thrane (1980), podem realizar certas funções gramaticais (como sujeito e objeto), certas funções semânticas (como agente e instrumento) ou certas funções retóricas (como tópico ou tema). Essas palavras, ou conjuntos de palavras, denominam-se $\mathrm{SN}$, e as mesmas constituem o conjunto de palavras que utilizaremos para servir como índice dos vídeos.

Quando o SN ficou constituído apenas de artigo + núcleo, em algumas vezes, o artigo foi suprimido. Essa medida foi tomada, pois o SACCA não possui só a pesquisa pelo conteúdo do vídeo, mas também tem a funcionalidade de criar um índice para cada vídeo (para que o usuário possa navegar no seu interior) e o excesso de artigos na frente do SN polui esse índice, não acrescentando um valor tão significativo para a palavra que justifique o seu uso. Além disso, segundo Kuramoto (1995, p. 3), "na língua portuguesa nem sempre um sintagma nominal é precedido de um determinante, enquanto, na língua francesa, a ausência de determinantes é uma rara exceção".

Foram definidos SN para toda a História do Brasil. Para o vídeo Colônia da série História do Brasil por Boris Fausto foram definidos os seguintes SN: Portugal Séc. XV, Expansão Marítima de Portugal, Os lusíadas - Camões, O que os portugueses buscavam, Expedições portuguesas, Caravela, Carta de Pero Vaz de Caminha, Chegada dos Portugueses no Brasil, Descobrimento do Brasil, Índios, Capitanias Hereditárias, cana-de-açúcar, Mão-de-obra, Travessia dos Escravos, Resistência dos negros a escravidão, Quilombo, Comércio de escravos, Holandeses no Brasil, Bandeirantes, Formação do povo brasileiro, Ouro, Imigrantes Brancos, Inconfidência Mineira, Inglaterra - potência dominante, Vinda da Família Real para o Brasil, Liberação do comercio Internacional, D.João VI, D. Pedro I e Independência do Brasil. O mesmo procedimento foi realizado para os outros vídeos de História do Brasil da TV Escola, das séries: "História do Brasil Por Boris Fausto", "Brasil 500 Anos: Um Novo Mundo na TV", "Brasil 500 Anos: O Brasil - Colônia na TV", "Brasil 500 Anos: O Brasil Império na TV", "Brasil 500 Anos: O Brasil - República na TV" e "Breve História das Capitais Brasileiras" totalizando 49 vídeos , que foram indexados e disponibilizados no CESTA.

\section{Conclusões}

Foi mostrado três sistemas que implementam a indexação de vídeos por conteúdo. $\mathrm{O}$ CESTA tem a vantagem de possibilitar a busca por palavra-chave e, além disso, possibilita que o aluno navegue, de forma hipertextual, nos diversos vídeos armazenados nesse repositório.

Sintagmas nominais é uma alternativa para a indexação de vídeos educacionais, principalmente quando este índice tem duas funcionalidades: realizar a consulta de uma determinada palavra-chave e navegar no interior do vídeo pelo índice criado. Nos SN as palavras continuam tendo sentido, ao contrário do que alerta Kuramoto (2002):

O processo de indexação extrai cada palavra do texto de um documento e o insere numa lista de palavras ordenadas, de forma a facilitar a recuperação de informação. Esse processo destrói, portanto, o trabalho intelectual do autor do referido documento. As palavras ao serem extraídas de um documento, de um texto, deixam de ter aquele valor específico atribuído e concebido pelo autor quando da sua redação. Essas palavras voltam a ter 
designações genéricas, ou seja, voltam a ter um conjunto de predicados, sem qualquer referência a um objeto ou fato da realidade extralingüística do autor (p.5).

A interação do sujeito ao navegar na internet ou no interior de um vídeo através dos SN pode possibilitar um aumento de conhecimento. Uma vez escolhida uma opção, o computador apresenta a informação disponível e o aprendiz pode refletir o conteúdo da opção, e esse conteúdo pode alterar suas estruturas cognitivas, decorrente de assimilações e acomodações.

Fischer (1998) também concorda com a quebra da linearidade do vídeo quando chama a atenção dos professores para não tratar o material televisivo em sala de aula com as mesmas deficiências com que se trata o texto literário: reducionista das diversas estratégias de linguagem e absolutamente linear e instrumental. Os vídeos indexados são uma solução de grande valia nesse contexto.

O professor terá disponível uma ferramenta que proporciona a facilidade de localizar o ponto exato em que se encontra uma palavra-chave dentro do vídeo, possibilitando que ele encontre de forma rápida o vídeo que melhor se insere na temática que ele deseja trabalhar. A ferramenta permite também a facilidade de o professor navegar dentro do vídeo através dos links, propiciando-lhe uma visão geral do que o vídeo trata.

O educador poderá planejar uma aula diferenciada na qual trabalhe com os SN dos vídeos em diversas atividades, como incluir o pedaço do vídeo na construção de páginas WEB pelos alunos, criar atividades diversas em que cada aluno fique responsável por um SN do vídeo (seja para compor um texto coletivo da turma, seja para complementar o assunto pesquisando sobre o item em outras fontes ou ainda para ele realizar uma explanação). Eles podem ser usados também como complemento às atividades escolares. Além disso, os vídeos indexados podem proporcionar um espaço para o professor explorar o lúdico e a pedagogia de projetos.

\section{Referências}

BAEZA-YATES, R.; RIBEIRO-NETO, B. Modern Information Retrieval. New York: ACM Press. 1999, 513 p.

CINTRA, A. M. M.; KOBASHI, N. Y.; LARA, M. L. G.; TÁlAMO, M. F. G. M. Para entender as Linguagens Documentárias. São Paulo : APB/Polis, 1994.

CLIR. Council on Library and Information Resources. Disponível em: $<$ http://www.clir.org> Acesso em: 21 dez. 2005.

COULON, D.; KAYSER, D. Informática e Linguagem Natural: uma visão geral dos métodos de interpretação de textos escritos. Brasília: IBICT, 1992.

FISCHER, R. M. B. O estatuto pedagógico da mídia: questões de análise. In Reunião Anual da ANPED, 1998. Disponível em: <http://www.educacaoonline.pro.br/ o_estatuto_pedagogico.asp?f_id_artigo=173> Acesso em: 16 nov. 2005.

GREFENSTETTE, G. Explorations in Automatic Thesaurus Discovery. Massachusetts: Kluwer Academic Publishers, 1994.

KURAMOTO, H. Sintagmas Nominais: uma Nova Proposta para a Recuperação de Informação, DataGramaZero - Revista de Ciência da Informação - v.3 n.1 
fev/2002. Disponível em: < http://www.dgz.org.br/fev02/Art_03.htm> Acessado em: 27 jun 2007.

KURAMOTO, H. Uma abordagem alternativa para o tratamento e a recuperação de informação textual: os sintagmas nominais, 1995. Ciência da Informação - Vol 25, número 2. p. 1 - 18. Disponível em: < http://eprints.rclis.org/archive/00003571/01/ Kuramoto1995.pdf > Acessado em: 27 jun 2007.

LAAN, R. H. V.; KRIEGER, M. G. Tesauro e terminologia: uma inter-relação lógica, 2002, 262 f. Tese (doutorado) - Universidade Federal do Rio Grande do Sul. Instituto de Letras. Programa de Pós-Graduação em Letras, Porto Alegre, BR-RS.

LAAN, R. H. V. et al. Avaliação de Descritores Relativos às Ciências da Informação: relato de pesquisa. Em Questão, Porto Alegre, 2004, v. 10, n. 2, p. 337-347, jul./dez.

LIBERATO, Y. G. A estrutura do SN em português: uma abordagem cognitiva. Tese (doutorado em Lingüística). UFMG, Departamento de Lingüística, Belo Horizonte, 1997.

MEADOW, C. T.; BOYCE, B. R.; KRAFT, D. H. Text Information Retrieval Systems. Academic Press. 2000, 364p.

MORAN, J. M. Desafios da televisão e do vídeo à escola. In Integração das Tecnologias na Educação, pages 96-100. Ministério da Educação, Seed, 2005.

NEVES, C. M. C. Próxima atração: a TV que vem aí. In: Integração das Tecnologias na Educação/ Secretaria de Educação a Distância. Brasília: Ministério da Educação, Seed. 2005, p. 88-91.

OSSES, J. R. Arquiteturas Cliente-Servidor para Disseminação de Dados Geográficos. São José dos Campos: INPE, 2000. 101 f. Dissertação (Mestrado em Computação Aplicada), Instituto Nacional de Pesquisas Espaciais São José dos Campos, 2000.

PAEPCKE, A. Digital Libraries: Searching is Not Enough. D-Lib Magazine, Stanford University. Disponível em: <http://www.dlib.org/dlib/may96/stanford/ 05paepcke.html> Acesso em: 21 dez. 2005.

PERINI, M. A.; FRAIHA, S.; FULGÊNCIO, L.; NETO, R. B. O SN em português: A hipótese mórfica. Belo Horizonte: Revista de Estudos de Linguagem - UFMG, Julho/Dezembro 1996. p.43-56

PRETTO, N. L. Uma escola sem/com futuro - educação e multimídia, Campinas: Papirus, 1996.

THRANE, T. Referential-Semantic Analysis: Aspects of a Theory of Linguistic Reference. Londres: Cambridge University Press. 1980, 256p. 